\title{
PENGEMBANGAN LKPD MODEL DISCOVERY LEARNING BERDASARKAN IDENTIFIKASI MANGROVE DI TWA PANTAI PANJANG BENGKULU
}

\author{
Mutia Lorena ${ }^{1 *}$, Kasrina ${ }^{1}$, dan Ariefa P Yani ${ }^{2}$ \\ ${ }^{1}$ Program Studi Pendidikan Biologi, Fakultas Keguruan dan Ilmu Pendidikan, Universitas Bengkulu \\ ${ }^{2}$ Program Studi Pendidikan IPA, Fakultas Keguruan dan Ilmu Pendidikan, Universitas Bengkulu \\ Email: mutialorena11@gmail.com
}

\begin{abstract}
Abstrak
Penelitian ini bertujuan untuk : (1) Mendeskripsikan jenis tumbuhan mangrove yang terdapt di Taman Wisata Alam Pantai Panjang kota Bengkulu, (2) Membuat desain LKPD berbasis Discovery Learning berdasarkan hasil pengembangan dari studi tumbuhan Mangrove di kawasan TWA Pantai Panjang Bengkulu. Jenis penelitian ini adalah penelitian dan pengembangan (Research and Development). Berdasarkan hasil studi tumbuhan mangrove yang ditemukan sebanyak 7 jenis yaitu Rhizophora apiculata, Sonneratia alba, Avicennia lanata, Bruguiera cylindrical, Lumnitzera littorea, Acanthus ebracteatus, Xylocarpus granatum. Hasil studi ini kemudian dikembangkan menjadi bahan ajar berupa LKPD yang divalidasi oleh 3 validator menunjukkan skor rata-rata 51,3 dengan persentase keseluruhan kriteria sangat valid 85,5 \% . LKPD juga diuji keterbacaan oleh 29 orang peserta didik kelas X SMA N 1 Bengkulu dengan hasil persentase 95,8\% dengan kriteria sangat valid. Berdasarkan persentase dari skor rata-rata hasil validasi oleh ahli dan uji keterbacaan dapat disimpulkan bahwa LKPD yang dikembangkan sangat valid dan sangat layak untuk digunakan sebagai bahan ajar di sekolah pada sub materi keanekaragaman hayati jenis X SMA.
\end{abstract}

Kata Kunci : Lembar Kerja Peserta Didik (LKPD), Discovery Learning, Mangrove

\begin{abstract}
This study aimed to : (1) Describing inventory of native mangrove species in Pantai Panjang Ecotoursim Park in Bengkulu city, (2) Developing students worksheet designs of the Discovery Learning based on studying of Mangrove vegetation $\mathrm{n}$ the area of Ecotourism park in Pantai Panjang. This type of research was the research and development. Based on the result of the study, the researcher found 7 native mangrove plant species, they were : Rhizophora apiculata, Sonneratiaalba, Avicennia lanata, Bruguiera cylindrical, Lumnitzera littorea, Acanthus ebracteatus, and Xylocarpus granatum. These data result then were developed to a teaching material in the form of students worksheet that validated by 3 validators. It showed an average score of 51.3 with the overall percentage of $85.5 \%$ with very valid criteria. This students worksheet also legibility tested by 29 students from the class of X SMA N 1 Bengkulu. Readability test result showed the percentage of $95.8 \%$ with very valid criteria. Based on the percentage of the result average score, it could be concluded that developed students worksheet was valid and appropriate to be used as a teaching material in schools, mainly in sub materials of Biodiversity in senior high school.
\end{abstract}

Keywords: Worksheet Students, Discovery Learning, Mangrove 


\section{PENDAHULUAN}

Provinsi Bengkulu memiliki banyak potensi lokal yang dapat dijadikan sebagai media pembelajaran. Salah satu potensi lokal yang dapat dijadikan sebagai media pembelajaran yaitu hutan mangrove yang terdapat pada kawasan Taman Wisata Alam (TWA) Pantai Panjang Kota Bengkulu. Salah satu materi pembelajaran di SMA kelas $X$ mempelajari tentang keanekaragaman hayati. Materi keanekaragaman hayati mempelajari keberagaman makhluk hidup pada tingkatan gen, jenis, dan ekosistem. Hal ini sesuai dengan KD pada RPP K 13 yaitu 3.2. Menganalisis data hasil obervasi tentang berbagai tingkat keanekaragaman hayati (gen, jenis dan ekosistem) di Indonesia (Permendikbud No 24 Tahun 2006).

Salah satu upaya dalam meningkatkan pemahaman konsep pada materi keanekaragaman hayati adalah dengan mengembangkan bahan ajar berupa Lembar Kerja Peserta Didik (LKPD) yang menyajikan pengidentifikasian struktur morfologi tumbuhan mangrove yang dapat dijadikan sebagai dasar pengelompokan keragaman tumbuhan mangrove. Hasil penelitian Rahmat (2015) menunjukan bahwa kualitas lembar kerja peserta didik (LKPD) pada materi keanekaragaman hayati termasuk dalam kategori sangat baik. Beberapa kekurangan yang ditemukan dalam LKPD Rahmat (2015) adalah pengunaan hanya sebatas gambar saja sehingga masih kurang memotivasi peserta didik untuk lebih tertarik dalam proses pembelajaran.

Hingga saat ini LKPD yang digunakan di sekolah saat ini khususnya di SMA Negeri 1 Kota Bengkulu cenderung hanya berisi materi dan latihan-latihan soal sehingga membuat peserta didik kurang terlatih untuk menemukan konsep-konsep pengetahuan yang ada.
Idealnya, LKPD harus menekankan pada proses untuk menemukan konsep, dan ada variasi stimulus melalui berbagai media dan kegiatan peserta didik, (Widjajanti, 2011). Sementara itu pengembangan LKPD berbasis Discovery Learning berdasarkan potensi lokal lingkungan sekitar masih sangat jarang di terapkan.

Discovery learning adalah suatu strategi belajar dimana peserta didik menemukan konsep dengan bimbingan guru dan menyempurnakan konsepkonsep yang telah diperoleh dari teori. Dalam Konsep Belajar, Discovery adalah pembentukan kategori-kategori atau konsep-konsep yang mengembangkan belajar peserta didik aktif dengan menemukan sendiri, menyelidiki sendiri, maka hasil yang akan diperoleh akan tahan lama dalam ingatan (Hosnan, 2014). Hasil penelitian Rahmat (2015) menyatakan bahwa dengan model ini dapat meningkatkan motivasi siswa dalam belajar sehingga pengetahuan / wawasan yang didapatkan menjadi berkesan dan mudah teringat serta terkonsep. Discovery learning dapat diimplementasikan melalui kegiatan pengamatan. Berpedoman dengan sintak-sintak pada Discovery Learning maka akan mempermudah menunutun peserta didik dalam proses pembelajaran dan menemukan konsep materi yang lebih mudah di pahami dan diingat. Berdasarkan latar belakang tersebut, maka penulis tertarik melakukan penelitian dengan judul "Pengembangan Lembar Kerja Peserta Didik Berbasis Discovery Learning Berdasarkan Identifikasi Mangrove Di Kawasan Taman Wisata Alam Pantai Panjang Bengkulu".

\section{METODE}

Jenis Penelitian ini merupakan penelitian dan pengembangan (Research and Development), yang terdiri dari bebrapa langkah utama yaitu : potensi 
dan masalah, pengumpulan data, desain produk, validasai desain oleh ahli, uji keterbacaan, revisi produk, penyempurnaan produk, uji pelaksaan lapangan, penyempuraan produk akhir dan implementasi (Sugiyono, 2008). Namun, pada pada penelitian ini hanya di batasi hingga tahap revisi desain akhir produk.

Penelitian telah dilaksanakan pada bulan November 2017 hingga April 2018 di Taman Wisata Alam Pantai Panjang Bengkulu untuk studi keanekaragaman tumbuhan mangrove, sedangkan Uji Validasi dan Uji keterbacaan LKPD dilaksanakan di Universitas Bengkulu dan SMA N 1 Bengkulu pada bulan April 2018. Objek penelitian ini adalah mangrove dan LKPD. Subjek uji keterbacaan adalah peserta didik kelas X IPA 3 SMA N 1 Bengkulu yang berjumlah 29 orang (10 lakilaki dan 19 perempuan).

Teknik pengumpulan data yang digunakan dalam penelitian ini adalah observasi, wawancara, angket dan studi pustaka.

Data hasil penelitian studi mangrove di TWA Pantai Panjang Bengkulu dianalisis secara deskriptif. Data hasil validasi (penilaian) yang didapatkan merupakan data kuantitatif yang akan diubah menjadi data kualitatif.

Data hasil studi mangrove diidentifikasi dan dianalisis secara deskriptif berdasarkan Laila dan Diah, (2013), Noor dkk (2006), Nugraha (2011), serta berbagai literatur atau jurnal yang relevan. Hasil validasi LKPD hasil pengembangan dan Uji Keterbacaan dianalisis menggunakan rumus

\footnotetext{
Presentase $=$

$\frac{\text { Jumlah hasil pengumpulan data }}{\text { Skor maksimal }} \times 100 \%$

(Ridwan, 2015)
}

Analisis skor yang telah didapatkan kemudian diinterpretasikan berdasarkan kriteria seperti pada Tabel 3.2.

Tabel 3.2 Kriteria Penilaian Hasil Validasi

\begin{tabular}{cc}
\hline Persentase & Kriteria \\
\hline $81 \%-100 \%$ & Sangat Valid \\
$61 \%-80 \%$ & Valid \\
$41 \%-60 \%$ & Cukup Valid \\
$21 \%-40 \%$ & Kurang Valid \\
\hline & (Ridwan, 2015)
\end{tabular}

\section{HASIL DAN PEMBAHASAN}

Berdasarkan hasil observasi lapangan di lokasi TWA Pantai Panjang Pulau Baai Bengkulu yang diamati, diperoleh data 7 jenis mangrove, yaitu Rhizophora apiculata, Sonneratia alba, Avicennia lanata, Bruguiera cylindrical, Lumnitzera littorea, Acanthus ebracteatus, Xylocarpus granatum.

\section{Pengembangan Desain LKPD}

Hasil studi observasi tumbuhan mangrove di Taman Wisata Alam Pantai Panjang Kota Bengkulu dikembangkan menjadi bahan ajar Lembar Kerja Peserta Didik yang mengacu pada Prastowo (2008) yaitu : Halaman depan (cover), Judul, Tujuan Pembelajaran, Konsep Materi, Prosedur Kerja, Hasil Pengamatan, Pertanyaan, dan Kesimpulan. Pengembangan desain LKPD ini juga menggunakan model Discovery Learning yang memberikan karakteristik pada LKPD dengan berpedoman pada sintak-sintak Discovery.

LKPD yang telah didesain divalidasi oleh dua orang dosen ahli, yaitu ahli bahan ajar dan ahli materi, serta seorang guru biologi SMAN 1 Bengkulu Tengah. Desain pengembangan LKPD yang telah dilakukan dapat dilihat pada Gambar 1 dan 2. 

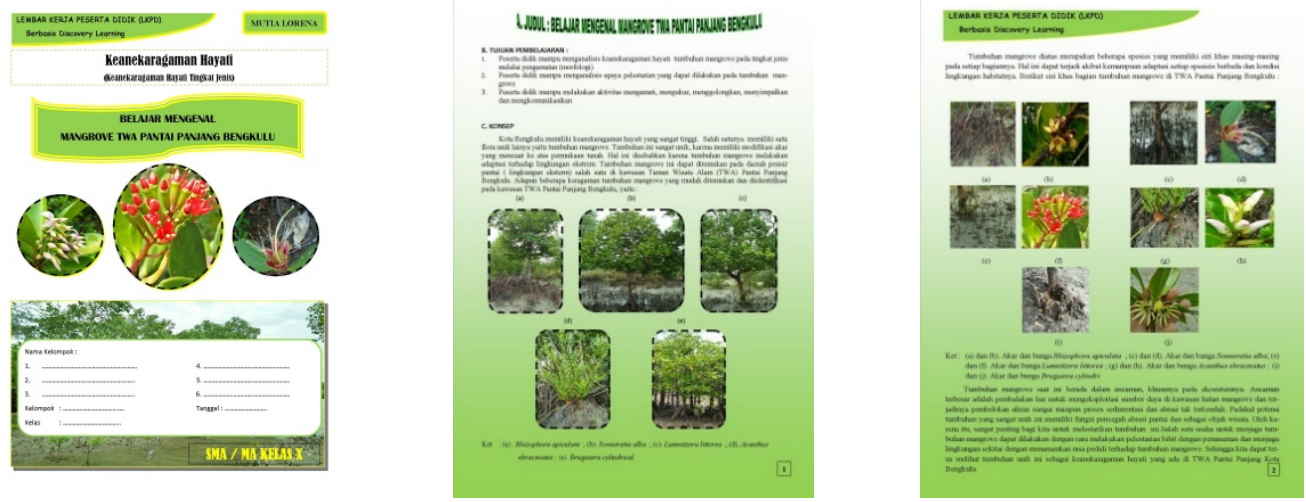

Gambar 1. Desain LKPD Sebelum Revisi
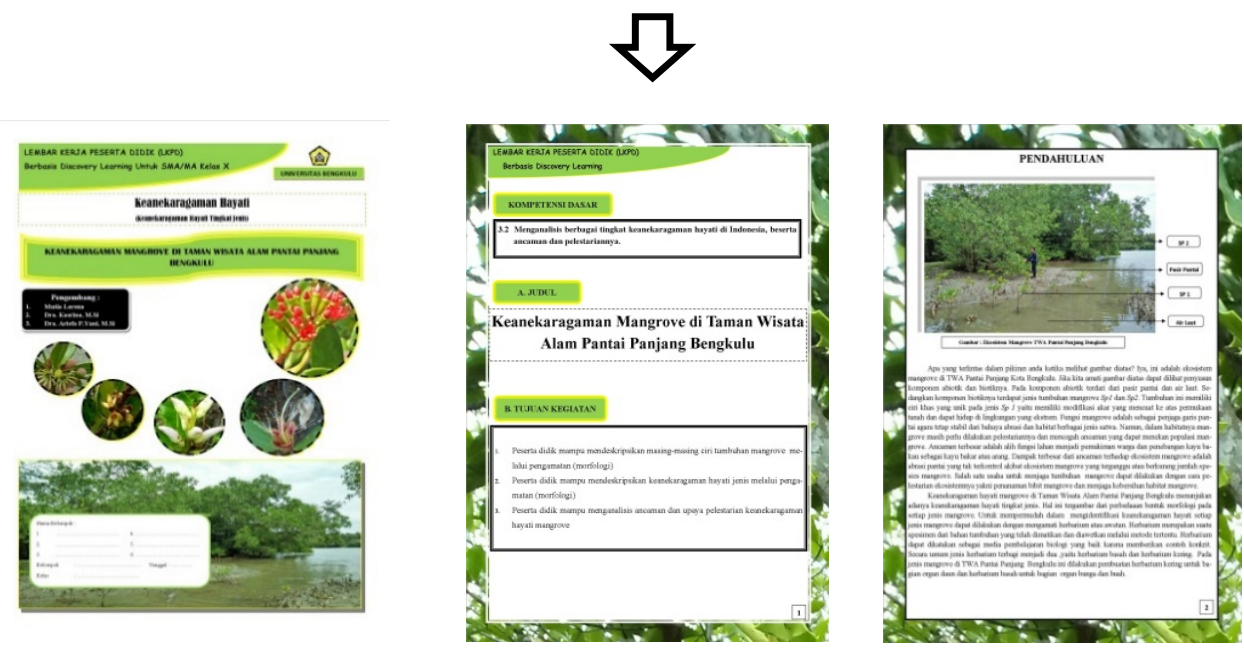

Gambar 2. Desain LKPD Setelah Revisi

Tabel 1. Hasil Validasi LKPD

\begin{tabular}{|c|c|c|c|c|c|c|c|}
\hline \multirow[b]{2}{*}{ No } & \multirow[b]{2}{*}{$\begin{array}{c}\text { Komponen yang } \\
\text { Divalidasi }\end{array}$} & \multicolumn{3}{|c|}{ Skor } & \multirow[b]{2}{*}{ Rerata } & \multirow[b]{2}{*}{ Presentase } & \multirow[b]{2}{*}{ Kriteria } \\
\hline & & $\begin{array}{l}\text { Ahli } \\
\text { Bahan } \\
\text { Ajar }\end{array}$ & $\begin{array}{l}\text { Ahli } \\
\text { Materi } \\
\text { Ajar }\end{array}$ & $\begin{array}{l}\text { Guru } \\
\text { Biologi } \\
\text { SMA }\end{array}$ & & & \\
\hline 1. & $\begin{array}{l}\text { Aspek Kelayakan } \\
\text { isi }\end{array}$ & 37 & 30 & 38 & 35 & $87,5 \%$ & $\begin{array}{c}\text { Sangat } \\
\text { valid }\end{array}$ \\
\hline 2. & $\begin{array}{l}\text { Aspek kelayakan } \\
\text { kebahasaan }\end{array}$ & 8 & 10 & 12 & 10 & $83,3 \%$ & $\begin{array}{l}\text { Sangat } \\
\text { valid }\end{array}$ \\
\hline 3. & $\begin{array}{l}\text { Aspek kelayakan } \\
\text { penyajian / } \\
\text { kegrafisan }\end{array}$ & 5 & 7 & 7 & 6,3 & $78,75 \%$ & valid \\
\hline & & erata ke. & uruhan & & & $85,5 \%$ & $\begin{array}{l}\text { Sangat } \\
\text { valid }\end{array}$ \\
\hline
\end{tabular}

Keterangan : Analisis validasi ahli bahan ajar, materi, dan guru Biologi memperoleh kriteria layak dengan kategori persentase sangat valid 
Hasil validasi kelayakan LKPD dari dari 3 orang validator dapat dilihat pada Tabel 1. Berdasarkan hasil validasi LKPD oleh ahli materi, ahli media dan guru Biologi diperoleh kriteria "Sangat Baik". Kriteria LKPD yang diperoleh dari masing-masing ahli yaitu layak dengan revisi sebelum dilakukan uji lapangan. Persentase keidealan LKPD dari aspek kelayakan isi, aspek kelayakan kebahasaan dan aspek kelayakan penyajian/kegrafisan diperoleh secara berurutan, yaitu $87,5 \%$; $83,3 \%$; dan
$78,75 \%$ dengan rerata keseluruhan sebesar $85,5 \%$. Dengan demikian, LKPD hasil pengembangan dari penelitian observasi tumbuhan mangrove layak untuk uji lapangan setelah revisi berdasarkan saran dari validator. Kemudian dilakukan uji keterbacaan LKPD hasil pengembangan di SMA Negeri 1 Bengkulu dengan jumlah peserta didik 29 Peserta Didik. Adapun hasil uji keterbacaan dapat dilihat pada Tabel 2.

\section{Tabel 2. Rekapitulasi Respon Peserta Didik Terhadap LKPD}

\begin{tabular}{|c|c|c|c|c|c|}
\hline \multirow[t]{3}{*}{ No } & Aspek & \multicolumn{4}{|c|}{ Jawaban } \\
\hline & \multirow{2}{*}{ Komponen kelayakan materi atau isi } & \multicolumn{2}{|c|}{ Ya } & \multicolumn{2}{|c|}{ Tidak } \\
\hline & & $\Sigma$ & $\%$ & $\Sigma$ & $\%$ \\
\hline 1. & Apakah susunan kalimat pada LKPD mudah dipahami dan jelas? & 28 & 96 & 1 & 0,4 \\
\hline 2. & Apakah petunjuk dan prosedur pada LKPD ini sudah jelas? & 28 & 96 & 1 & 0,4 \\
\hline 3. & $\begin{array}{l}\text { Apakah materi menarik dan menambah wawasan tentang } \\
\text { tumbuhan mangrove? }\end{array}$ & 26 & 89 & 3 & 0.11 \\
\hline 4. & $\begin{array}{l}\text { Apakah gambar di dalam LKPD memiliki kejelasan dan } \\
\text { kelengkapan keterangan? }\end{array}$ & 29 & 100 & - & - \\
\hline 5. & $\begin{array}{l}\text { Apakah contoh tumbuhan mangrove yang disajikan pada LKPD } \\
\text { sudah cocok dengan keanekaragaman tingkat jenis? }\end{array}$ & 27 & 93 & 2 & 0,7 \\
\hline 6. & Apakah penyajian materi mendorong rasa keingintahuan? & 26 & 89 & 3 & 0,11 \\
\hline 7. & $\begin{array}{l}\text { Apakah Bahasa yang digunakan pada LKPD komunikatif dan } \\
\text { mudah dipahami? }\end{array}$ & 27 & 93 & 2 & 0,7 \\
\hline 8. & $\begin{array}{l}\text { Apakah penyusunan layout dan desain cover atau sampul depan } \\
\text { menarik? }\end{array}$ & 29 & 100 & - & - \\
\hline 9. & Apakah tata letak gambar dan tulisan jelas dan baik? & 29 & 100 & - & - \\
\hline 10. & Apakah hasil cetakan berkualitas baik dan jelas? & 29 & 100 & - & - \\
\hline & Jumlah rerata persentase & & & & \\
\hline & Kategori & & Sang & Baik & \\
\hline
\end{tabular}

Uji keterbacaan LKPD pada 29 peserta didik memperoleh rerata persentase 95,8 $\%$, dengan kategori "sangat baik". Penelitian lain oleh Junaidi (2014) menunjukkan hasil pengembangan LKPD yang dikategorikan sangat baik atau layak, dimana LKPD yang dikembangkan hanya sebatas LKPD umum tanpa berkarakeristik dengan model pembelajaran apapun. Selain itu LKPD yang disajikan hanya sebatas menampilkan gambar tanpa menyajikan herbarium, sedangkan pada desain LKPD model Discovery Learning ini menyajikan herbairum basah dan kering untuk menambah motivasi peserta didik dalam pembelajaran.

Berdasarkan hasil revisi dan penilaian dari para validator, dapat dilihat perubahan dari desain yang telah dibuat. Seperti yang telah disajikan bahwa sebelum revisi desain LKPD pada bagian cover hanya menyajikan 3 jenis bunga 
mangrove, sedangkan setalah revisi menyajikan 5 jenis bunga mangrove, karena berdasarkan saran validator bahwa cover harus menggambar keseluruhan isi dari LKPD. Kemudian pada desain sebelum revisi pada hal kedua dan hal ketiga menyajikan warna background (latar) yang terlalu gelap sehingga kurang jelas jika di baca. Maka setelah direvisi desain latar digantikan dengan warna yang lebih terang agar memotivasi peserta didik untuk membacanya.

Pengembangan desain LKPD yang telah dilakukan dimulai dari penyusunan LKPD dengan model reconstruction atau rekontruksi. Menurut Prastowo (2015) LKPD model rekontruksi memiliki kegiatan seperti melengkapi suatu tabel berdasarkan data yang diperoleh, baik dari pengamatan langsung atau grafik. Pembelajaran menggunakan LKPD membantu siswa untu mengkonstruksi pengetahuan ke dalam otak mereka melalui tahapan berpikir, yaitu mengamati, menganalisis kemudian menyimpulkan. Kegiatan mengamati karakter morfologi dari contoh tumbuhan mangrove yang didapat dari hasil observasi merupakan usaha untuk membuat materi lebih bersifat konret. Selain itu, dibantu juga dengan pertanyaan analisis untuk mendorong siswa agar mampu menemukan konsep keanekargaman hayati tingkat jenis dari pengamatan variasi bunga dan buah tumbuhan mangrove.

Pengembangan desain LKPD ini dilakukan berbasis Discovery Learning. Menurut Kusuma (2015), model pembelajaran discovery merupakan suatu cara untuk mengembangkan belajar siswa aktif dengan menemukan sendiri, menyelidiki sendiri, maka hasil yang akan diperoleh akan tahan lama dalam ingatan. Dengan berpedoman dengan sintak-sintak padaDiscovery Learning maka akan mempermudah menuntun peserta didik dalam proses pembelajaran dan menemukan konsep materi yang lebih mudah di pahami dan diingat. Adapun sintak-sintak dari model Discovery Learning yaitu stimulation (pemberian rangsangan), problem statement (identifikasi masalah/pernyataan), data collection (pengumpulan data), data processing (pengolahan data), verification (pembuktian), generalization (penyimpulan) (Cahyo, 2013).

Aspek yang dikembangkan pada LKPD ini meliputi desain, tujuan kegiatan, pendahuluan materi, kegiatan siswa, pertanyaan dan struktur. Desian LKPD dirancang dengan mengunakan ukuran A4, kepadatan halaman yang rendah dan penomoran yang jelas antara judul dan sub judul. Tujuan kegiatan pada lembar kerja peserta didik disesuaikan dengan kompetensi dasar 3.2 agar peserta didik mampu melakukan kegiatan pengamatan, menjelaskan ciri-ciri setiap contoh mangrove dan konsep keanekaragaman hayati tingkat jenis serta melakukan kegiatan keterampilan proses dasar (mengamati, mengukur, mengglongkan, dan menyimpulkan). Sedangkan untuk bagian pendahuluan materi LKPD menggunakan data hasil studi tumbuhan mangrove di TWA Pantai Panjang Kota Bengkulu. Prosedur kegiatan dirancang agar peserta didik dapat menjelaskan ciri tumbuhan mangrove dan keanekaragaman hayati tingkat jenis melalui pengamatan, serta melatih keterampilan proses dasar). Pertanyaan disusun untuk mengkonfirmasi hasil pengamatan peserta didik dan disesuaikan dengan sasaran (peserta didik kelas $X$ SMA). Setelah penambahan halaman depan untuk menarik minat belajar peserta didik, maka struktur lembar kerja peserta didik yang dikembangkan menjadi seperti berikut : 1 . Halaman depan (cover); 2. Judul; 3. Tujuan pembelajaran; 4 . Konsep materi; 5. 
Prosedur kerja; 6. Hasil pengamatan; 7. Pertanyaan; 8. Kesimpulan.

Produk LKPD yang baik dan tepat yaitu ketika telah dilakukan beberapa tahap validasi, antara lain oleh ahli bahan ajar, ahli materi, dan guru Biologi kelas $X$. Tujuan dari tahap ini adalah melihat kelayakan LKPD sebelum dilakukan uji coba lapangan. Hasil validasi oleh beberapa ahli tersebut secara keluruhan memberikan penilaian bahwa LKPD yang dikembangkan "sangat baik" dan layak dengan revisi diujicoba. Menurut Widarmayanti (2015) yang diharapkan dari validasi adalah masukan perbaikan LKPD. Saran yang diberikan oleh validator adalah acuan untuk perbaikan produk LKPD tersebut agar sesuai dengan aspekaspek pembelajaran, seperti tujuan pembelajaran, kegiatan LKPD, tampilan LKPD dan pertanyaan analisis. Widyantini (2013) juga menguatkan, bahwa LKPD memang seharusnya memenuhi syarat konstruksi terkait kejelasan struktur kalimat, penggunaan bahasa, keselarasan antara tujuan pembelajaran.

Uji lapangan keterbacaan LKPD dilakukan dengan jumlah 29 siswa kelas $X$ MIPA 3 SMAN 1 Kota Bengkulu. Tahapan ini bertujuan untuk melihat keefektifan dan kekurangan pada LKPD, seperti kejelasan kalimat serta tingkat pertanyaan. Menurut Emzir (2012) berpendapat bahwa uji coba mengatakan bahwa ujicoba dilakukan untuk menguji dan melihat kekurangan pada LKPD dan melakukan revisi kembali agar dapat mencapai kompetensi dasar tujuan pembejaran.

\section{PENUTUP}

Simpulan

Berdasarkan hasil observasi di Taman Wisata Alam Pantai Panjang Bengkulu, ditemukan sebanyak 7 jenis tumbuhan mangrove, yaitu Rhizophora apiculata, Sonneratia alba, Avicenni alanata, Bruguiera cylindrical, Lumnitzera littorea, Acanthus ebracteatus dan Xylocarpus granatum. Ketujuh jenis ini memiliki karakter khas masing-masing pada ciri morfologi dari bagian habitus, tipe akar, bentuk batang, daun, bunga dan buah.

Lembar Kerja PesertaDidik (LKPD) hasil pengembangan dari studi tumbuhan mangrove "LAYAK" digunakan dalam pembelajaranBiologi pada materi keanekaragaman hayati yang dibuktikan dengan hasilvalidasi oleh ahli materi, media dan guru Biologi.

\section{Saran}

Perlu dilakukan penelitian lebih lanjut mengenai tumbuhan mangrove dengan daerah lain yang kondisi habitatnya sama seperti pantai panjangprovinsi Bengkulu.

Penggunaan LKPD hasil penelitian tumbuhan mangrove dapat dicoba pada model dan metode pembelajaran lain yang berbeda pada penelitian ini.

\section{DAFTAR PUSTAKA}

Cahyo, Agus N. (2013). Panduan Aplikasi Teori-Teori Belajar Mengajar Teraktual dan Terpopuler. Jogjakarta : DIVA Press

Emzir. (2012). Metodologi Penelitian Pendidikan Kuantitatif dan kualitatif. Jakarta. Rajawali Press.

Hosnan. Dipl. Ed. (2014). Pendekatan Saintifik dan Kontekstual Dalam Pembelajaran Abad 21. Bogor: Ghalia Indonesia.

Junaidi (2014). Identifikasi Komposisi Vegetasi Mangrove Di Kawasan Wisata Alam Bangko-Bangko Kabupaten Lombok Barat. Jurnal Penelitian UNRAM 18 (2), Diakses 22 Juli 2018.

Kusuma, Tiani Alfi. Indawati. Alex. (2015). Model Discovery Learning Disertai Teknik Probing Prompting Dalam PembelajaranFisika di MA. Dalam 
Jurnal Pendidikan Fisika 3 (4), Di Akses 13 November 2017

Laila dan Diah Lestari P. (2013). Mangrove Pilar yang Terlupakan. Tangerang. PT Nusantaralestari Ceriapratma

Noor,Rusila, Y., M. Khazali, dan I N.N. Suryadiputra. (2006). Panduan Pengenalan Mangrove di Indonesia. PHKA/WI-IP, Bogor.

Nugraha, Rudijanta Tjahja (2011). Seri Buku Informasi Dan Potensi Mangrove Taman Nasional Alas Purwo. Banyuwangi. Balai Taman Nasional Alas Purwo.

Permendikbud No 24 Tahun 2016 Tentang Kompetensi Inti dan Kompetensi Dasar Untuk Pendidikan Dasar dan Menengah

Prastowo, Andi. (2015). Panduan Kreatif Membuat Bahan Ajar Inovatif. Menciptakn Metode Pembelajaran yang Menarik dan Menyenangkan.Yogyakarta: DIVA Press.

Rahmat. (2015). Pengembangan Lembar Kerja Peserta Didik (LKPD) Biologi Berbasis Potensi Lokal Hutan Mangrove dengan Strategi Discovery Learning pada Materi Pokok Keanekaragaman Hayati untuk Kelas X di SMA Negeri 1 Popayato. Jurnal Pendidikan Universitas Negeri Gorontalo.

Riduwan. (2013). Skala Pengukuran Variabel-variabel Penelitian. Bandung : ALFABETA.

Sugiyono. (2008). Metode Penelitian Pendidikan: Pendekatan Kuantitatif, Kualitatif, dan Research and Development. Bandung: Alfabeta.

Widarmayanti, R. P., Susantini, E., Ambarwati, R. (2015). Profil Validitas LKS BerbasisKeterampilan Proses Pada Subpokok Bahasan Invertebrata Untuk Kelas X SMA. Jurnal Bioedu 4 (1).
Widyantini, T. 2013. Penyusunan Lembar Kegiatan Siswa (LKS) sebagai Bahan Ajar. Pusat Pengembangan dan Pemberdayaan Pendidik dan Tenaga Kependidikan (PPPPTK) Matematika. Yogyakarta: PPPPTK Matematika 